\title{
Teacher Support and Student's Self-efficacy Beliefs
}

\author{
Sidney N. Mitchell \\ The University of Maine \\ sid.mitchell@maine.edu \\ Julie N. DellaMattera \\ The University of Maine \\ Julie.dellamattera@umit.maine.edu
}

\begin{abstract}
The present study investigated the role of teacher support and its influence on middle school student's self-efficacy beliefs. A statewide survey of 9,702 urban and rural middle school students found that teacher support declined across the middle school years and that this had negative effects on student self-efficacy beliefs. The data do show that girls received more support than did boys and that girls also had generally higher selfefficacy beliefs than did boys. Overall, the results show that middle school teachers can do more in fostering self-efficacy, particularly in boys, and maintaining support throughout a student's middle school experience. The present study of student's perceptions of teacher support over the middle school years is an important step in our ability to understand the complex ways in which teachers influence student's selfefficacy beliefs.
\end{abstract}

Beginning middle school represents an important change in the lives of many young adolescents. It not only signifies a change in grade, but also the transition from an elementary school where they have one teacher for all subjects to an environment where they have multiple teachers. This transition, typically involves adjusting to a new school with different rules, norms of behavior, and increased academic expectations (Eccles, 2004). Previous research in the area of school transitions has shown that transitions may bring a host of problems for students, which include, among other things, lower academic achievement, less teacher support, and lower self-efficacy beliefs (Eccles, 2004; Klem \& Connell, 2004; Wigfield \& Eccles, 1994). In this paper, we report the results of a statewide survey conducted in Maine on urban and rural middle school students' perceptions of teacher support and its relationship to students' self-efficacy.

\section{Teacher Support}

A factor that has been identified as crucial for the development of students' sense of self-efficacy is the support they receive from their teachers. Teacher support can come in many forms, from helping with tasks to showing care and concern for students' welfare and well-being, but traditionally teacher support is defined as students' beliefs that their teachers care about and will help them when needed (Trickett \& Moos, 1973). It

Journal of Contemporary Issues in Education, 2010, 5(2), pp.24-35

ISSN 1718-4770 @ 2010 University of Alberta

http://ojs.educ.ualberta.ca/index.php/jcie/ 
has been found that when students perceive support from their teachers, they are more likely to be engaged in class and in their studies (Hughes, Zhang, \& Hill, 2005; Patrick, Ryan, \& Kaplan, 2007), expend greater effort and persist longer at difficult tasks (Goodenow, 1993; Wentzel, 1994; 1997), and are more likely to seek help from their teachers when they encounter difficulties (Marchand \& Skinner, 2007; Newman \& Schwager, 1993).

Teacher support and other support-related behaviors are particularly important factors in encouraging or hindering the development and maintenance of student selfefficacy and motivation (Moos, 1978; Ryan, Stiller, \& Lynch, 1994; Wentzel, 1997), as well as developing overall positive attitudes toward school (Evans, 1998; Wentzel, 1997). Indeed, Marchant, Paulson, and Rothlisberg (2001) reported that overall student motivation and self-efficacy beliefs were enhanced by teacher responsiveness to student needs within a supportive environment, and this was subsequently related to students' grades.

Student perceptions of teacher support, has also been linked with a host of psychological states, such as positive emotional adjustment in school (Roeser, Eccles, \& Sameroff, 1998), and higher self-esteem and lower levels of depression (Colarossi \& Eccles, 2003). Positive associations have been found between perceived support from teachers and several factors including, improved social skills, academic competence, selfconcept, and adaptive skills (Demaray \& Malecki, 2002). For example, students who perceived low teacher support exhibited more problem behaviors and fewer positive behaviors than students who perceived moderate or high teacher support (Demaray \& Malecki, 2002). Moreover, the quality of teacher-student relationship in classrooms as early as first grade has been shown to predict peer acceptance the following year (Hughes $\&$ Kwok, 2006). Accordingly, researchers are considering more and more the role and nature of teacher support on student behavior, and academic outcomes (Demaray \& Malecki, 2002; Malecki, \& Elliott, 1999; Marchand \& Skinner, 2007).

\section{Self-Efficacy}

Self-efficacy is one of the primary mechanisms of human agency, and none is more significant or persistent than people's beliefs in their ability to manage their own thinking and to exercise control over events that affect their lives (Bandura, 1997; 2001). Self-efficacy is commonly defined as "...the belief in one's capabilities to organize and execute the courses of action required to manage prospective situations" (Bandura, 1995, p. 2). While other factors may serve as guides and motivators, they are ultimately entrenched in the fundamental belief of one's ability to produce desired effects. Belief in one's capabilities in turn influences one's feelings, thinking, and actions from birth to death (Bandura, 1997, 1986; Heckhausen \& Schulz, 1995; Little \& Lopez, 1997; Skinner, 1997). Self-efficacy beliefs regulate functioning through cognitive, motivational, and affective processes, and these beliefs, in turn, affect whether people see themselves in a positive or negative light (Bandura, 1986).

In school, a high sense of self-efficacy has been associated with higher overall academic achievement and a greater liking for school (Bandura, 2001; Little \& Lopez, 1997; Skinner, 1996; Skinner, Schindler, \& Tschechne, 1990; Skinner, ZimmerGembeck, \& Connell, 1998). In contrast, students with a low sense of self-efficacy often doubt their abilities and are more likely to avoid difficult tasks, give up easily when faced 
with difficulty, have generally low aspirations, and weak commitment to self-chosen goals (Bandura, 2001; Pajares, 1996; Schunk \& Pajares, 2002).

The extant research highlights the importance of teacher support in aiding students learning and the development of self-efficacy. In this report, we present the results of a statewide survey of Maine middle school students' perceptions of the support they receive from teachers and how this is related to their sense of self-efficacy we also investigated if there are differences between urban and rural students in their perceptions of teacher support and its relation to self-efficacy.

\section{$\underline{\text { Participants }}$}

\section{Methods}

Data from a survey on student's aspirations in relationship to the support they received from teachers were used for this study. Participants were 9,702 students in Maine in grades 6 through 8 with an average age of 12.73. The students attended public schools in rural and urban school districts located throughout Maine, and were predominantly Caucasian (90.4\%), and approximately $4.6 \%$ of the students identified Native American. The sample was almost equally divided by gender 4,869 girls and 4,833 boys, and by grade (see Table 1).

Table 1: Gender by Grade

\begin{tabular}{ccccc}
\hline & \multicolumn{4}{c}{ Grade } \\
\hline Gender & 6 & 7 & 8 & Total \\
\hline Female & 1696 & 1560 & 1613 & 4869 \\
Male & 1686 & 1561 & 1586 & 4833 \\
Total & 3382 & 3121 & 3199 & 9702 \\
\hline
\end{tabular}

\section{$\underline{\text { Instrument }}$}

The Students Speaks II: My Education My Future Scale (Tu, et al., under review) was used to survey student's perceptions of teacher support and how teacher support is related to self-efficacy. The teacher support scale consists of 12 items that are responded to on a 7-point Likert-type scale anchored by strongly disagree to strongly agree. Sample items include "I have at least one teacher who makes me feel better when I'm sad or upset," "My teachers respect my opinions," and "My teachers believe I can succeed in what I want to do." The self-efficacy scale consists 12 items that are responded to on a 7point Likert-type scale. Sample items include "I believe that I can achieve whatever I set my mind to," "I am taking steps now to work toward my goals after high school" and "I have one teacher that I can talk to," and "My teachers tell me I do a good job when I try my best." Computing the mean responses to all twelve items derives scores used in the analyses. Higher means indicate greater agreement with the item.

\section{Procedure}

The Students Speaks II surveys were sent to schools and administered by school personnel (teachers and teacher assistants) and researchers connected with the study. A formal written protocol was provided to each school detailing directions on how to administer the scale; this was done to ensure uniform administration across schools. The surveys were completed during class time and students were given enough time to 
complete the scales and have any questions answered. No students refused to complete the scales. Completed surveys were returned to the researchers for scoring and analysis.

\section{Results}

\section{Relationship of Teacher Support and Student Self-Efficacy}

The relationship between the amount of perceived teacher support and students' self-efficacy beliefs shows a strong positive relationship between these two variables $r$ $(9,381)=.581, p .<.001$. The amount of variability explained in this relationship equals $33.7 \%$, which is considered to be quite strong (Cohen, 1988). More specifically, these findings illustrate that one third of the variability in students' perceived self-efficacy beliefs are explained by the support they receive from teachers. Clearly, teacher support is crucial for student success and engagement in school. Next we analyzed the results between urban and rural and socio-economic status.

Maine has 16 counties, each of which was sorted into one of four categories based on population and socioeconomic factors (see figure 5). The term urban was used distinguish a county that had over 100 people per square mile and rural was used for those counties that had under 100 people per square mile. The designator "prosperous" was assigned to those counties that had less than $14 \%$ of its population receiving food stamps and less than $40 \%$ of its students receiving free or reduced school lunch. The designator "poor" was assigned to those counties that had more than $14 \%$ of its population receiving food stamps and more than $40 \%$ of its students receiving either free of reduced lunch.

Table 2: Urban and Rural Counties by Socio-economic status.

\begin{tabular}{|c|c|c|c|}
\hline \multicolumn{2}{|r|}{ Urban } & \multicolumn{2}{|l|}{ Rural } \\
\hline ¿̀ & Androscoggin & $\begin{array}{l}\text { Aroostook } \\
\text { Franklin } \\
\text { Oxford } \\
\text { Piscataquis } \\
\text { Somerset } \\
\text { Waldo } \\
\text { Washington }\end{array}$ & 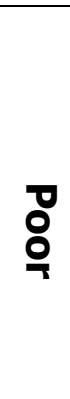 \\
\hline $\begin{array}{l}\frac{n}{3} \\
\frac{0}{ \pm} \\
\frac{0}{0} \\
\frac{0}{2}\end{array}$ & $\begin{array}{l}\text { Cumberland } \\
\text { Kennebec } \\
\text { Knox } \\
\text { Sagadahoc } \\
\text { York }\end{array}$ & $\begin{array}{l}\text { Lincoln } \\
\text { Hancock } \\
\text { Penobscot }\end{array}$ & 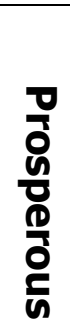 \\
\hline & Urban & Rural & \\
\hline
\end{tabular}


We analyzed the differences between urban and rural on students reports of self-efficacy and found a moderate difference $\mathrm{F}(14,9,561)=6.19, \mathrm{p}<.001$. Rural students reported greater levels of self-efficacy beliefs $(M=5,71)$ compared to urban students $(M=5.67)$. These differences were also seen when we looked at socio-economic status between urban and rural students. Rural poor students reported higher levels of self-efficacy beliefs $(M=5.71)$ compared to their urban poor counterparts $(M=5.69)$, and rural prosperous students also reported higher levels of self-efficacy (M-5.72) compared to their urban prosperous counter parts $(\mathrm{M}=5.65)$.

The results for overall teacher support were significant $F(14,9,602)=14.55$, p. $<.001$, however, unlike the results for self-efficacy, we found higher overall means for urban students on teacher support $(\mathrm{M}=5.11)$ compared to their rural counterparts $(\mathrm{M}=5.06)$. Rural poor students reported lower levels of teacher support $(\mathrm{M}=5.01)$ compared to their urban poor counterparts $(M=5.20)$, however, rural prosperous students reported higher levels of teacher support (M-5.12) compared to their urban prosperous counter parts $(\mathrm{M}=5.03)$. While the mean differences between the groups on these measures are small the large sample size suggests that there are real differences between the perceptions of urban and rural students on these measures.

Additionally, the relationship between students' self-efficacy beliefs and their grade point average (GPA) was significant $r(8,603)=0429, p .<.001$ which accounts for a moderate to large relationship between the two variables (18.4\%; Cohen, 1988).

Finally, the relationship between teacher support and students' GPA was also significant $\mathrm{r}(8,498)=.265, \mathrm{p}<.001$. Still, the amount of variance explained by teacher support on students' GPA was 7\%, which is considered to be a small to moderate relationship. The results further show that higher levels of teacher support are correlated with higher levels of self-efficacy in students and moderately with higher student GPAs. Girls reported higher GPAs than did boys, although we do not know if greater teacher support is the cause of higher GPAs and self-efficacy beliefs or vice versa. Nevertheless, the trends reported here are consistent with similar findings on efficacy beliefs from across the nation (Goodenow, 1993; Hughes, Zhang, \& Hill, 2006; Newman \& Schwager, 1993; Patrick, Ryan, \& Kaplan, 2007; Wentzel, 1994; 1997).

Grade Level

Students' reported levels of teacher support do not appear to be mediated by their current grade. The results indicate that teacher support in middle school students remained virtually equal from grade 6 to grade 8 (see figure 1) as does students' selfefficacy (see figure 2). 
Figure 1: Level of teacher support by grade

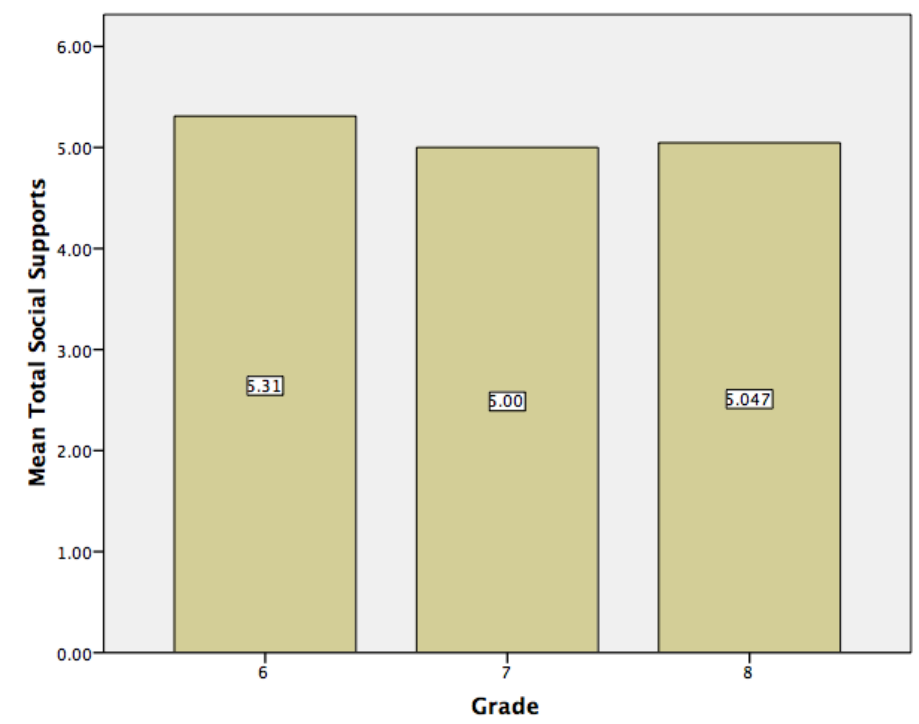

Figure 2: Level of students' self-efficacy by grade

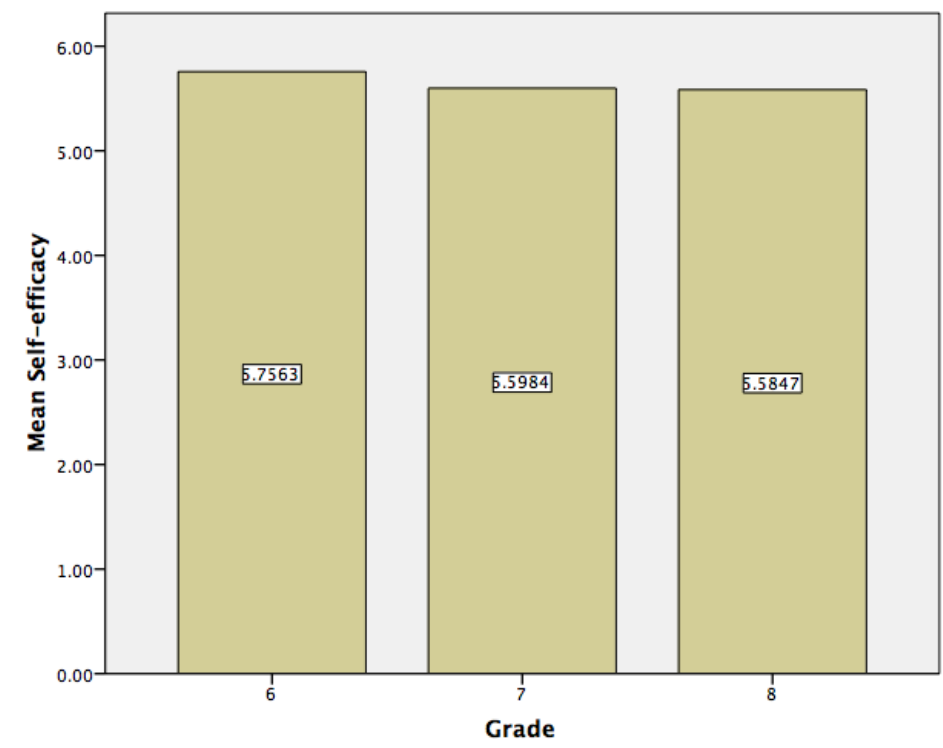

\section{Gender}

Girls in this study reported higher levels of self-efficacy than did boys (see figure 3 ) and greater perceptions of teacher support (see figure 4). However, for both girls and boys we saw a steady decline of self-efficacy from grade 6 to 8 . The majority of the drop was from grade 6 to 7, and only a slight drop of grade 7 to 8 . Moreover, boys reported levels of self-efficacy are significantly lower than girls. Typically, we tend to see that boy's self-efficacy is equal to, or higher, than girl's self-efficacy beliefs. Across several studies, findings have consistently shown that girls' and boys' self-efficacy beliefs follow gender role stereotypes. Boys report greater ability and interest in mathematics and science, whereas girls report greater ability and interest in language arts and writing (Meece, Glienke, \& Burg, 2006). The present results from this study suggest a positive change in girl's self-efficacy beliefs away from gender stereotypical ways. However, the 
results also strongly suggest that middle schools could be doing more to promote selfefficacy beliefs in girls and boys.

Figure 3: Level of Self-Efficacy by Gender and Grade

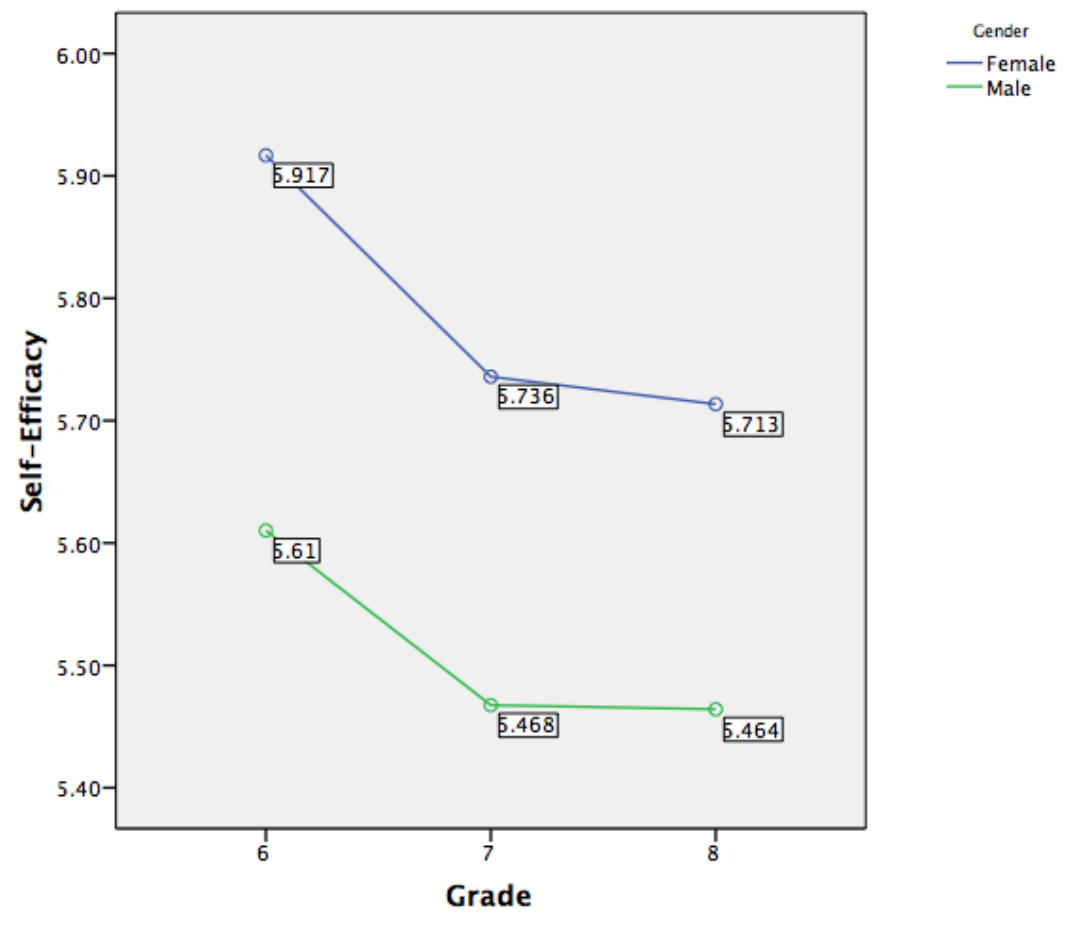

Similarly, we saw a pronounced decrease in the levels of teacher support from grade 6 to 7 and a slight increase from grade 7 to 8 (see figure 4). Overall, girls reported greater teacher support than did boys across all grade levels.

Figure 4: Level of teacher support by gender and grade

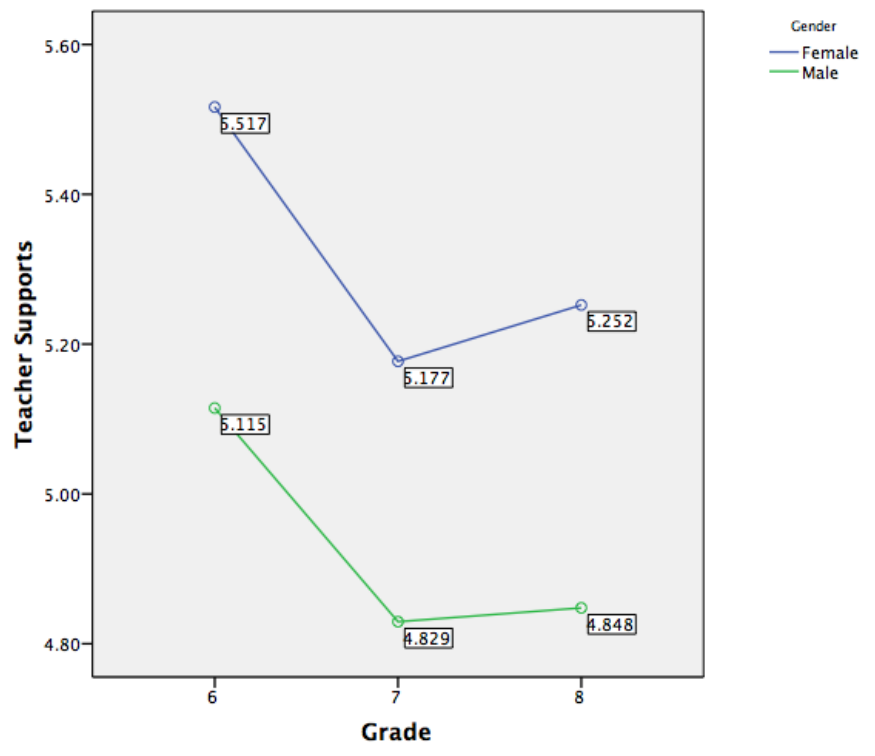




\section{Discussion}

The purpose of the present study was to analyze students' perceptions of teacher support and its effects on student's self-efficacy beliefs in middle school. More specifically, we wanted to show that perceived teacher support influences student's selfefficacy beliefs. The findings from this survey provide additional support for the work that schoolteachers are doing with middle school students in terms of developing their sense of self-efficacy. Conversely, the findings do indicate that for many students who hold lower self-efficacy beliefs that they are not receiving the same level type of support from teachers that their higher efficacy peers are receiving. Moreover, boys lag behind girls in the level of support they receive and report lower levels of self-efficacy than do girls. As previously mentioned, students with a low sense of self-efficacy tend to doubt their abilities and are prone to avoid demanding tasks, give up quickly when faced with difficulty, have lower aspirations than their higher achieving peers, and a weak commitment to self-chosen goals (Bandura, 2001; Pajares, 1996; Schunk \& Pajares, 2002).

The results also show that the level of perceived teacher support declines as student's progress through middle school; however, the research has been consistently clear on this point, for students to be successful in school they need to feel supported by their teachers (Klem \& Connell, 2004). Though the findings concerning the mean level changes during the middle school grades in student self-efficacy beliefs could be due to transitional periods, the findings from the three grades and from urban and rural districts and regions indicate that that teacher support is important at all grade levels and not just transitional years. Overall, the results show that middle school teachers can do more in fostering self-efficacy, particularly in boys, and maintaining support throughout a student's middle school experience.

\section{Conclusion and Recommendations}

This study showed that perceived teacher support influenced student's selfefficacy beliefs. Three interesting issues emerge in the data. The first is that perception matters. If students believe they are receiving more teacher supports, their reported selfefficacy beliefs are higher. The second is that boy's perception of teacher support is that they are receiving less teacher supports than girls. The third is that rural poor student's perception is that they are receiving less teacher overall support than all other students. Each of these is discussed below.

\section{Public relations management}

This study showed a significant positive relationship between the amount of perceived teacher support and student's reported level of self-efficacy. If a student thinks their teachers are more supportive, their level of self-efficacy is higher. From this, it is clear that middle school teachers are aware of and working toward providing a variety of teacher supports to all their students particularly in the grade 6 to 7 transition. Teacher supports can range from the simple "good job" to the more time consuming $~$ writing

articles to the local newspaper to point out and praise the good work a student or group of 
students is doing. Support can be a pat on the back, a copy of a newspaper article about an event of interest to a specific student, or a lunchtime discussion with a small focus group of students to talk about career opportunities.

Additionally, all staff members in a school need to work together to help students understand that they need to advocate for themselves. If students are not feeling supported by their classroom teacher then the student should speak with another trusted adult in the school or community who can help them get their needs met. This could be another teacher, a guidance counselor, or a parent. Sometimes a student and teacher do not suit each other well; not every teacher will mesh with every student. However, as the adult, the teacher should be sure that each student has someone that they can talk with and connect with. The school is a support community, a large interconnected team that both teachers and students need to take advantage of so that everyone is supported.

\section{Performance management}

Girls reported both higher levels of self-efficacy and greater levels of perceived teacher supports than did boys. This study is not implying that teachers are, in fact, giving boys less support, just that boy's perception is that they are receiving less support than girls. Perception is a curious thing. These results suggest two courses of action for middle school teachers. One is that they actually need to offer more teacher supports to boys, or two, teachers need to be sure boys are clear about when teacher supports are being given.

The first, teachers offering more supports, is perhaps the easier of the two. This involves teachers being more cognizant of the supports they are offering to students in their classrooms and making an effort to reach out to the boys.

The second, teachers being more transparent with the supports they are offering so that boys realize they are in fact being supported, is a bit more complicated. The assumption is that boys may need a more tangible and concrete picture of how teachers are supporting them. This necessitates teachers using performance management as a way to help students know that they are recognized and acknowledged for the work that they do. Performance management requires ongoing communication between a teacher and a student to accomplish defined goals. For a middle school teacher hoping to effectively and visibly support boys, this process includes one-on-one meetings between the student and the teacher to clarify expectations, identify and set goals, provide feedback, and evaluate the results (Berkeley University of California, 2010). Teachers need to clearly outline these steps to students, set meetings to discuss progress, and have students document the steps and analyze the results.

\section{Rural school management}

Rural students reported extremes on measure of teacher support. Rural poor students reported lower levels of teacher support compared to their urban poor counterparts, but rural prosperous students reported higher levels of teacher support compared to their urban prosperous counter parts.

Level of Perceived Teacher Support

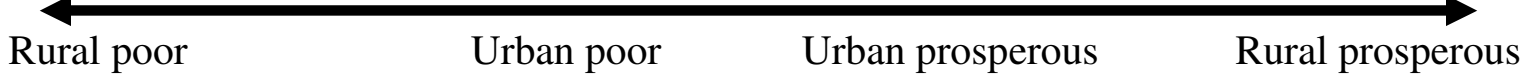

This is called the "dog bone effect" in which common elements are in the middle with larger, more extreme results appearing on either end. This demonstrates that urban 
students perceive that they are receiving average teacher support, whether they are from poor or prosperous counties, while rural students are more inclined to perceive that they are very under supported or very much supported. Again, perception can be deceiving. What this dog bone continuum tells us is that rural poor children do not perceive that they are receiving the teacher supports they may need. The inability of middle school students in rural poor counties to get the teacher supports they need, whether real or imagined, is cause for concern.

Real or imagined, community involvement is the answer. When school communities are rural and poor, resources are hard to find due to either a deficiency in funding and/or a lack of availability. One resource that is definitely smaller in rural areas is the number of teachers. This may result in a student may have difficulty finding an adult that they feel comfortable with. School administrators need to free up teachers and other adults in the school so that they have time to meet with students on an individual basis and be sure that each student has someone that they are connected to.

Additionally, perceptions of lesser teacher supports need to be addressed and changed. In rural poor communities the school is often the center of the community and often community members are deeply and emotionally involved in the school culture. Community involvement can have a negative impact on school culture if the community has a pessimistic view of the importance of schooling on positive futures for its students. The upside to an involved and engaged community is that a strong belief, a loud public outcry, can change public opinion.

In rural poor communities people have to work harder to make less go farther. Teachers and schools need to be better at using volunteers, finding resources that meet a variety of student needs, and creating a positive presence in the community. Schools need to keep community members informed about the good work that teachers are doing, and the resulting positive impact on students. There are a variety of ways to spread the word: a weekly "good news" article about great things students are doing could appear in the local newspaper; a "student of the week" on the school marquee; a monthly student art or math or science show where community members are invited. The possibilities are endless.

The study of student's perceptions of teacher support in the middle school classroom over the middle school years is an important step in our ability to understand the complex ways in which teachers influence student's self-efficacy beliefs. Future research should investigate individual and classroom level effects of teacher practices on students' perceptions and beliefs. 


\section{References}

Bandura, A. (1986). Social foundations of thought and action: A social cognitive theory. Upper Saddle River, NJ, US: Prentice-Hall, Inc.

Bandura, A. (1994). Self-efficacy. In V. S. Ramachaudran (Ed.), Encyclopedia of human behavior (Vol. 4, pp. 71-81). New York: Academic Press. (Reprinted in H. Friedman [Ed.], Encyclopedia of mental health. San Diego: Academic Press, 1998).

Bandura, A. (1995). Exercise of personal and collective efficacy in changing societies. In A. Bandura (Ed.), Self-efficacy in changing societies, (pp. 1-45) New York, NY, US: Cambridge University Press.

Bandura, A. (1997). Self-efficacy: The exercise of control. New York, NY, US: W. H. Freeman/Times Books/ Henry Holt \& Co.

Bandura, A. (2001). Social cognitive theory: An agentic perspective. Annual review of Psychology, 52, 1-26.

Berkeley University of California (2010). Guide to Managing Human Resources. Retrieved September 2, 2010 from http://hrweb.berkeley.edu/guide/performance.

Colarossi, L. G., and Eccles, J. S. (2003). Differential effects of support providers on adolescents' mental health. Social Work Research, 27, 19-30.

_Demaray, M. \& Malecki, C. (2002).The relationship between perceived social support and maladjustment for students at risk. Psychology in the Schools, 39(3), 305-316.

Eccles, J. (2004). Schools, academic motivation, and stage-environment fit. In R. M.Lerner \& L.Steinberg (Eds.), Handbook of adolescent psychology (2nd ed., pp. 125-153). New York: Wiley.

Evans, R. (1998). Changing families changing schools. ERIC Clearinghouse, ED 434749. $13 \mathrm{p}$.

Goodenow, C. (1993). Classroom belonging among early adolescent students: Relationships to motivation and achievement. Journal of Early Adolescence, 13(1), 21-43.

Heckhausen, J., \& Schulz, R. (1995). A life-span theory of control. Psychological Review, 102(2), 284-304.

Hughes, J. \& Kwok, O. (2006). Classroom engagement mediates the effect of teacherstudent support on elementary students' peer acceptance: A prospective analysis. Journal of School Psychology, 43(6), 465-480.

Hughes, J., Zhang, D., \& Hill, C. (2006). Peer assessments of normative and individual teacher-student support predict social acceptance and engagement among lowachieving children. Journal of School Psychology, 43(6), 447-463.

Klem, A. \& Connell, J. (2004). Relationships matter: Linking teacher support to student engagement and achievement. Journal of School Health, 74(7), 262-273.

Little, T. D., \& Lopez, D. F. (1997). Regularities in the development of children's causality beliefs about school performance across six sociocultural contexts. Developmental Psychology, 33(1), 165-175.

Malecki, C. K. \& Elliott, S. N. (1999). Adolescents' ratings of perceived social support and its importance: Validation of the Student Social Support Scale. Psychology in the Schools, 36, 473-483.

Marchand, G. \& Skinner, E. (2007). Motivational dynamics of children's academic helpseeking and concealment. Journal of Educational Psychology, 99(1), 65-82. 
Marchant, G. J., Paulson, S. E., \& Rothlisberg, B. A. (2001). Relations of middle school students' perceptions of family and school contexts with academic achievement. Psychology in the Schools, 38, 505-519.

Meece, J., Glienke, B., \& Burg, S. (2006). Gender and motivation. Journal of School Psychology, 44(5), 351-373.

Moos, R. (1978). A typology of junior high and high school classrooms. American Educational Research Journal, 15, 53- 66.

Newman, R. \& Schwager, M. (1993). Students' perceptions of the teacher and classmates in relation to reported help seeking in math class. The Elementary School Journal, 94(1), 3-17.

Pajares, F. (1996). Self-efficacy beliefs in academic settings. Review of Educational Research, 66(4), 543-578.

Patrick, H., Ryan, A. \& Kaplan, A. (2007). Early adolescents' perceptions of the classroom social environment, motivational beliefs, and engagement. Journal of Educational Psychology, 99(1), 83-98.

Roeser, R. W., Eccles, J. S., \& Sameroff, A. J. (1998). Academic and emotional functioning in early adolescence: Longitudinal relations, patterns, and prediction by experience in middle school. Development and Psychopathology, 10, 321-352.

Ryan, R. M., Stiller, J. D., \& Lynch, J. H. (1994). Representations of relationships to teachers, parents, and friends as predictors of academic motivation and selfesteem. Journal of Early Adolescence, 14, 226-249.

Schunk, D. \& Pajares, F. (2002). The development of academic self-efficacy. In A. Wigfield \& J. Eccles (Eds.), Development of achievement motivation, pp. 15-31. San Diego: Academic Press.

Skinner, E. A. (1996). A guide to constructs of control. Journal of Personality \& Social Psychology, 71(3), 549.

Skinner, E. A. (Ed.). (1997). Planning and perceived control. Mahwah, NJ, US: Lawrence Erlbaum Associates, Publishers.

Skinner, E. A., Schindler, A., \& Tschechne, M. (1990). Self-other differences in children's perceptions about the causes of important events. Journal of Personality and Social Psychology, 58(1), 144-155.

Skinner, E. A., Zimmer-Gembeck, M. J., \& Connell, J. P. (1998). Individual differences and the development of perceived control. Monographs of the Society for Research in Child Development, 63(2-3).

Trickett, E., \& Moos, R. (1973). Social environment of junior high and high school classrooms. Journal of Educational Psychology, 65(1), 93-102.

Wentzel, K. R. (1994). Relations of social goal pursuit to social acceptance, classroom behavior, and perceived social support. Journal of Educational Psychology, 86(2), 173-182.

Wentzel, K. R. (1997). Student motivation in middle school: The role of perceived pedagogical caring. Journal of Educational Psychology, 89, 411-419.

Wigfield, A., \& Eccles, J. (1994). Children's Competence Beliefs, Achievement Values, and General Self-Esteem: Change across Elementary and Middle School. Journal of Early Adolescence, 14 (2), 107-138. 